\title{
International Students' Perspectives on e-Learning During COVID- 19 in Higher Education in Australia: A Study of an Asian Student
}

\author{
Yuqi Lin and Ha Nguyen \\ Monash University, Clayton, VIC, Australia \\ ylin0083@student.monash.edu \\ ha.nguyen1@monash.edu
}

\begin{abstract}
Given that online higher education shows no sign of abating during the COVID-19 pandemic in Australia, understanding the nature of e-learning and e-learners in this particular setting is much needed. However, little is known about the e-learning approaches that international students apply, or about how they experience the process of e-learning. This article is a critical reflection on the misalignment between an international student's (Author 1) e-learning behaviours and the expectation of online education. It outlines the autoethnographic method and employs self-study to explore why Author 1 behaves in a certain way with particular reference made to the Biggs' 3P model. In so doing, the study attempts to shed light on the values and interests of international students that have been silenced in the discourse of e-learning design in Australian universities. With the aim of obtaining a profound insight into the effectiveness of e-learning, the present study challenges the notion that the virtual university is a means of achieving educational equality; it suggests the potential of online education in undermining the social inclusion agenda of internationalised universities. The findings show that while the participant could engage with the curriculum to some extent, there are signs of disconnection, isolation and emotional instability associated with the establishment and development of the e-learning environment. Illustrations of these emerging issues could help educators better understand the downside of e-learning and e-practice by identifying various influential elements, including individuals' socioeconomic status, cultural heritage and environmental learning settings. The study points out that international students' education outcomes could be compromised, and expectations could be unfulfilled via e-learning. Thus, there is a further need to prepare learners for e-learning environments.
\end{abstract}

Keywords: e-learning; COVID-19; international students' perspectives; Australian university; 3P model; virtual university

\section{Introduction}

The COVID-19 pandemic has caused a fundamental change in the way that educators transform knowledge, meaning an increasing number of international students would participate in Australia's education programs via adapting e-learning and e-practice. Since April 2020, Australian universities have unveiled online courses and taken on the form of virtual universities as an emergency plan to alleviate the impact of COVID-19 (Australian Government Department of Education Skills and Employment, 2020). By definition, a virtual university refers to a higher education institution that offers educational courses and learning options via a well-structured webportal on the Internet (Shahtalebi, Shatalebi and Shatalebi, 2011). In such settings, virtual classes, modules and real-time tutorials and discussion forums are delivered by computer applications and multimedia technologies, while examinations and laboratory work are carried on through virtual-reality programming (Shatalebi, Shatalebi and Shatalebi 2011). However, these changes are likely to raise an additional set of challenges for international students who are expected by educators to practice e-learning in a professional manner and to utilise these digital tools to assist their e-learning..

The level of satisfactory learning experiences in Australian universities could be affected by the advocation of elearning and the utilisation of e-practice. Statistically, the export of education contributes $\$ 37.6$ billion to the Australian economy (Parliament of Australia, 2019). Apart from financial rewards, the motivation for universities to enact this practice is aligned with the value that the higher education ranking system places on the ratio of international students (QS topuniversity, 2020). While these three elements are arguably intertwined, the designs of e-learning may rely on assumptions about international students and these students' perceived education quality. In the field of education research, studies on Asian students' cross-border educational experience and studies on virtual universities are extensive. Yet there has been little literature combining both areas - research on Asian students' cross-border learning experiences in virtual universities is scarce. Moreover, the existing studies are limited to students' use of technology, with little attention paid to their learning strategies. In an effort to narrow this gap, the current study seeks to reclaim some of the lost and disregarded voices of international students. 
In an attempt to help fill the void, the present case study sets out to offer a qualitative account of how knowledge is acquired in an Australian virtual university from the perspective of an international student. In so doing, the direct impact of the pandemic on the learning experience during the pandemic will be analysed. Possible learning strategies to optimise the learning outcome of a cohort of Asian international students in e-learning settings will be proposed.

In summary, the context has been described and the aims of the study have been clarified. The following section will present a literature review regarding recent studies on the virtual university and the 3P model. By way of illustration, a critical framework for learning theory, Biggs' 3P model (Biggs, 1990) will be utilised as a means of examining the learning strategies, attitudes and practices of the virtual university regarding contextual factors, such as knowledge delivery patterns. The study will then offer an introduction to autoethnographic research methods followed by a critical discussion about the challenges of practicing e-learning. It argues that the consideration of e-learning design with other factors, such as cultural background and learning styles, would be an important avenue to explore given that the utilisation of e-learning is becoming a new normal.

\section{Biggs's 3P model in E-learning}

In order to analyse the participant's e-learning behaviour in an organised way, the development of virtual universities, the studies of e-learning experience and Biggs's (1990) 3P model will be illustrated in this section.

Since the unprecedented development of the virtual university, many scholars have prioritised different aspects of increasingly complex and diverse e-learning. As such, a body of literature around the e-learning environment is offered as an approach for effective online education (Cho et al., 2015). Initially, the research studies learners in a micro-level environment and focuses explicitly on course-related topics, such as learning content, assessment and interaction modes (Hew and Cheung, 2012; McPherson and Bacow, 2015). Subsequently, as learners are simultaneously contained in a macro-level environment, research has been expanded to account for a broader scope, including online education theories, educational policies, professional development of faculties and the impact of labour markets (Bernard et al., 2004). Furthermore, several studies have examined the demographic factors of successful online learners (Ke and Kwak, 2013; Keller and Karau, 2013). While these studies offer considerable insights for effective e-learning, research in international student experiences is limited in the examination of ethnic factors. In other words, there have been few studies on the alignment between e-learning approaches and international students' learning expectations with reference to their original socioeconomic status in Australia's virtual university settings.

In the process of e-learning and e-practice, learners, educators and institutions are considered as the core elements of the virtual university. From the learners' perspectives, attending virtual universities reduces timespace barriers and alleviates the burden of commuting from home to campus. However, e-learners are likely to feel isolated in the learning environment in the virtual university through the lack of interpersonal communication (Wang and Chiu, 2008). Roger (2003) finds that online learners may be subject to negative social influences and perceptions regardless of their ability to adapt to technology and innovation. In an ongoing Australian cohort investigation into the learning outcomes of higher education (Australian Department of Education and Training, 2017b), online learners are 2.5 times more likely than their traditional peers to withdraw from courses without a certification. Meanwhile, the retention and completion rates for online learners are less than 80 percent of traditional ones (Australian Department of Education and Training, 2017b). Arguably, the lack of interaction with peers and educators means that online learners may not be able to effectively narrow the gap between the result of independent learning and the level of potential development (Vygotsky, 1998). Moreover, learning is essentially a process of socialisation in which learners are expected to connect to both the learning content and macro-environments (Vygotsky, 1998). However, it is worth noting that theories of social constructivism only partially identify the social nature of learning. They do not consider the sociocultural influence that international students may be vulnerable to in their host countries, especially if there is a mismatch between the Asian students' underdeveloped dispositions and western virtual universities' prerequisites (Zhao and McDougall, 2008). Thus, it is crucial to have conversations with e-learners as a means to examine the education quality in virtual universities.

Helmi (2001) predicts that the only proper solution to improve the effectiveness of online courses is to empower the learners. In this regard, research into students' perception of e-learning is important. This is even more so in Australia, where the higher education industry has been internationalised. According to the Australian Bureau 
of Statistics (2020), imports of services, which consists of education and tourism, have fallen by $12.8 \%$ since the pandemic. At the national level, the Australian Gross Domestic Product declined 0.3\%, which is a resemblance to the situation in 2009, when Australia was enmeshed in the Global Financial Crisis (Australian Bureau of Statistics, 2020). Thus, exploring the perspective of international students would be useful in developing the quality of education in the virtual university, in that the financial crisis caused by the global pandemic might be alleviated in this way.

It is clear that understanding international students' learning behaviours in Australia's virtual universities could offer insights into the current practice of online education and provide a possible solution for the development in education and national economic situations. Therefore, instead of presenting an over-generalised description of e-learning, a framework that values individual difference - the 3P model - is considered as a suitable starting point for the present study. Specifically, this model was devised by Biggs (1990) to delineate the relationship between the fluid nature of learning motivations, the contextual components of the environments, strategies for participating in learning, and academic performance. It identifies three stages of learning: (1) presage, containing study-related factors and factors from teaching contexts; (2) process, including various learning approaches; and (3) product, referring to learning outcomes (Biggs, 1990). The model sheds light on the diversity of learners and provides variables in predicting academic performance other than ability. Thus, it is employed as a theoretical framework for the present study. It deepens the analysis into and discussion about the challenges that international online learners may have in ever-complex virtual university contexts. Generally, the current study builds on and contributes to development in e-learning. While the study focuses on Australia's virtual universities, it may be a source of reference for other countries. While the existing literature examined demographical factors, such as age (Ke and Kwak, 2013) there has not been an attempt to interpret e-learners' success or failure based on their perceptions. As such, this study provides additional insights into e-learning, and its aims are as follows:

1. identifying the gap between international students and the prerequisites of online education in terms of digital literacy and emotional development

2. exploring the (mis)alignment between the expectation of Australian universities' online education and international students' learning practices

3. offering suggestions on online education research from the perspective of international students

\section{Method}

\subsection{Autoethnography as a research method}

The autoethnography methodology was employed for its unique advantages in exploring the experiences, relationships and identities of a particular individual. Such a methodology has re-emerged as the means to understand personal problems from a naturalistic stance with the belief that human beings are interrelated (Bullough and Pinnegar, 2001). By definition, autoethnographers have developed four major branches, namely autoethnography (Hayano 1979), evocative autoethnography (Ellis, 1997), analytic autoethnography (Anderson, 2006) and collaborative autoethnography (Chang, Ngunjiri and Hernandez, 2013). In the present study - using the $3 \mathrm{P}$ framework to investigate international students' e-learning practices - we draw from analytic and evocative autoethnography. Specifically, the former one, analytic autoethnography has the following characteristics: "a full member in the research setting, a full member in the researcher's published texts, and committed to an analytic research agenda focused on improving theoretical understanding of broader social phenomena" (Anderson 2006, p.21). As such, analytic autoethnography provides a pathway for researchers to engage with authentic e-learning experiences and theoretical discussions - the 3P model.

The latter one, evocative autoethnography, is "a genus of writing and research, autoethnography starts with personal experiences and studies 'us' in relationships and situations" (Ellis, 1997, p.13). This method allows the authors to move back-and-forth between the e-learning experience and self and observe the wider context of that experience, such as Australian higher education (Ellis, 2007). In this way, this study would carefully examine Author 1's notes, reflections and supporting materials. In particular, several rounds of self-interrogation and self-examination would be conducted to document e-learning behaviours. Moreover, consistent with autoethnographic techniques, the current study invests Author 2, an outsider, in the study. She worked closely with Author 1 throughout the research, including the design of the study, collection and analysis of the data. By so doing, this study could avoid self-indulgent introspection (Chang, 2008) so that a transparent picture of professional activity can be depicted, and a thoughtful view formulated. By combining analytic and evocative autoethnography, we believed the trustworthiness of the current study could be increased. 
While autoethnographic studies have been criticised for lacking significance (Bullough and Pinnegar, 2001), they have the power to present the practice from insiders and develop the understanding of the theory in a more detailed manner. Therefore, the current study treats autoethnography as a powerful and critical tool for education studies. In particular, such a method has the potential to bridge the understanding of international students by un-silencing their voices (Adams, Holman and Ellis, 2015). In this regard, it could address the crisis of representation, as it is important for stakeholders, such as educators and university administrators, to understand international students' feelings, lives, struggles and relationships through the eyes of insiders. As such, the study attempts to present not only insights and interpretations from a personal perspective, but also become the voice of international students and seek to improve the e-learning situation for this particular cohort.

\subsection{Data collection and analysis}

Education study is rooted in a particular cultural, political and social context (Freebody, 2003). The present study is associated with the study of international students' e-learning during the COVID-19 pandemic. The primary data source of the present study was Author 1's field notes and her personal diary of e-learning experiences, including her reactions and reflections on e-practices. Based on her self-observations and reflections, she offered a general description of her e-learning behaviours, which exposed her vulnerability as a means to understand the emotions that have been generated during the process and presented her perceptions of elearning outcomes. As the course progressed, the interactions with Author 1's tutor become frequent, and these conversations regarding course contents, learning methods helped her advance in the study, and shape her understanding of being an e-learner. Thus, discussions with tutors were also be documented as an example of her development of e-learning ability. Other data sources included: conversations with parents about her elearning progress, the formal evaluation from chief examiners, especially the written feedback, and Author 1's reflections on her e-learning experience after finishing the course.

A thematic analysis (TA) is preferred in this study. Theoretically, TA is known for its flexibility in categorising data, identifying patterns, and describing data with rich detail (Braun and Clarke, 2006). In the present study, the data is to be collected by following Biggs' (1990) 3P model. In this sense, the analysis is driven by a specific theory and thus tends to place emphasis on certain aspects of the data (Braun and Clarke, 2006). In this regard, Author 1 's documents would be placed according to Biggs's definition and then sorted into three categories - presage, process and product (Biggs, 1990). Moreover, the recurrent themes will be captured to explore the relations between an Asian student's values, characters, learning habits and the results of e-learning. Hence, the analysis follows TA's principles - recurrence and importance - and concentrates on the exploration of social capital theory at a semantic level (Braun and Clarke, 2006).

The analysis starts with the familiarisation of the data based on Braun and Clarke's (2006) guidelines. This practice is viewed as the primary interpretative act, where the meaning may be generated (Braun and Clarke, 2006). After these initial preparations, all materials were read and re-read in a careful manner to capture a general understanding and develop initial ideas (Braun and Clarke, 2006). Driven by the theoretical interest, the primary practice of coding aims to work systematically through the data with special attention to related theoretical areas (Braun and Clarke, 2006). In this way, the author attempts to code for themes that can be identified from the data, while focusing on the core inquiry - the gap between international students' experiences and the prerequisite of online education in terms of digital literacy and emotional development; and the (mis)alignment between the expectation of Australian universities' online education and international students' learning practices. In an attempt to answer these questions, the narrative and supporting materials were examined carefully to preserve the validity of the interpretation (Braun and Clarke, 2006). Following the initial coding, in the third stage, the focus would be on searching for the broader level of themes, including classifying codes and relevant data into potential themes (Braun and Clarke, 2006). As such, TA enhances the interpretation of the materials as it offers ample room for researchers to identify emerging concepts in a systematic approach.

\subsection{The Author 1's context}

The participant of this study was Author 1, an international learner in an Australian university. She received her Bachelor's degree in Mainland China and enrolled in an Australian university. Similar to the majority of international students, studying abroad is perceived as a path for attending a world-class university and an 
adventure of gaining a new cultural and social experience (King and Sondhi, 2018). This life choice is a reflection of Author 1's cultural heritage, family and social backgrounds and previous experience.

Culture is a critical factor that influences an individual both consciously and unconsciously. Recently, culture has been identified as an influential element in the construction of self, which, in turn, is reflected in individuals' behaviours (Harrington and Liu, 2002). In this study, Author 1 comes from an Eastern culture -Confucianism where self-criticism is commonly used in psychological processes (Harrington and Liu, 2002). Such a tendency is led by Confucian values - humility and submission (Harrington and Liu, 2002). In this sense, Author 1 is likely to view herself as a subordinate to a group, such as a student of a particular unit, and follow the rules accordingly. Meanwhile, while the self-criticising nature may help Author 1 to find her areas of weakness and motivate her to work on them accordingly; it can also prevent her from challenging the rules and to remain silenced (Harrington and Liu, 2002). Compared to Eastern cultures, Western ones promote the understanding of an independent self and encourage individuals to be "expressed in public and confirmed in private" (Harrington and Liu, 2002, p. 39). These distinctions between two cultural norms make cross-cultural communication more complicated, and thereby could lead to exacerbate Author 1's inner conflicts for lacking the ability to balance the differences.

In contemporary China, society is experiencing dramatic economic and social changes and a particular group, the affluent Chinese middle class, has emerged. This group is known for being more economically capable and globally oriented. As indicated by Eileen Yuk-ha (2013), Author 1 could be categorised in the second-generation middle class which constitutes the majority of international students' group. By definition, she would be more familiar with the English language than working-class peers and aspire to educational opportunities and living experience in Anglophone countries. Meanwhile, Author 1's participation in the Australian education programs reflects the changes in China's labour market. As indicated by Lin and Chan (2020), Chinese tertiary enrolment has expanded more than tenfold since the 1990s, which affects graduates' employment in a negative way. In other words, China's massification of higher education has led to unemployment and underemployment (Lin and Chan, 2020). Given that, middle-class families are keen to send their children abroad in the hope of gaining advantages in the highly competitive market. Following Bourdieu's (1984) analysis, this strategy aims to distinguish the second-generation middle class, such as that of Author 1 , from others in terms of different educational achievement. As such, Author 1 is expected to achieve academic high-performance to obtain leverage in the market.

While Author 1 grew up in the era of technology and is termed as digital native (Anon, 2011), it is questionable to assume that she can adjust easily to e-learning. Considering her previous learning experience in the early 2000s, e-teaching and learning practices in China are still in their infancy (Hamidi et al., 2011). As such, she could not be viewed as a capable e-learner who has sufficient digital literacy. In line with that, scholars highlight the phenomenon that students are struggling to accept the new technologies in educational practices (Arbaugh, 2004; Greene and Copeland, 2014). Reportedly, delayed feedback, unfamiliar learning environments and lack of the sense of belonging are decreasing e-learners' learning motivations. Given that, Arbaugh (2004) argues that students need to be provided with time to transit from traditional classroom learning to e-learning. However, in the current context, Author 1 needs to adjust to the e-learning model quickly in the time of COVID-19. Therefore, she is striving to modify her learning behaviours while learning to conduct cross-cultural communication.

As aforementioned, Author 1 is facing a number of challenges in her e-learning. Her transition from traditional learning to e-learning is a focal point of discussion about an international students' real-life experience in COVID19.

\section{Author 1's E-learning experience: achievements, frustrations and developments}

In Australia, educational courses in virtual universities generally combine both synchronous and asynchronous forms. In the current setting, Moodle, an online learning system, is employed as the sole delivery platform. Within the platform, synchronous online tutorials are conducted, and asynchronous online discussion forums are set.

\subsection{Insecurity, lack of confidence and loneliness}

In an attempt to have learner-learner interactions, I experienced a fear of expressing myself in an unfamiliar space. In the class, I was encouraged to consider myself as a social member, and integrate my personal 
experiences, manners and the course context into the e-learning process. However, I was not particularly confident about my English writing, and therefore preferring to simply read my peers' posts rather than actively engage in the forum. During the process, I would draft several replies for the online forum. Yet before submitting, I would start to question myself: will my peers be offended by my words? Will I make a good impression on the readers? I felt so insecure that I eventually deleted all of them. I was both eager to connect with people and scared to make any moves.

Gradually, participating in e-learning environments as a lurker became my default mode in engaging knowledge content in the online course. On the plus side, lurking allowed me to connect with the learning content on Moodle, while keeping track of peers' learning process and sustain a basic level of involvement in discussion forums. However, to maintain this invisible presence, I found myself allocating hours of online time to avoid the feeling of being left behind. As the email record shows, I received 299 notifications from the forum. Taking $31^{\text {th }}$ of March for example, I received 26 notifications which start from 8:18 AM to 11.28 PM. Unfortunately, I experienced an information overload that directly led to certain negative emotions, such as anxiety and frustration. These negative emotions prompted me to examine my learning preferences. From the perspective of perceptual learning style preferences, I preferred visual learning modes. From the perspective of sociological learning style preferences, I preferred to work by myself in a highly organised manner. As a result, negative emotions - anxiety and frustration - could be detected when I was overwhelmed by the myriad of e-learning sources and struggling with some technical problems. For many days, I spent hours in mind-wandering. The image - me as a prisoner who is never able to leave the house, keeps hovering in my mind. I felt so powerless in everything.

Moreover, I could sense that my goal was evolving. Unavoidably, I had to deal with family pressure, as my parents constantly expressed their high expectations of me - earning social approval for the family by attaining a high academic achievement. Moreover, they were concerned about the devaluing of western education quality through the form of e-learning, especially my development in employability. My mom was calling me and said:

You really need to work harder and try to advance yourself in Australia. It is really hard to get a decent job in China, not to mention you want to live in cities, such as Shanghai. Do you know my colleague's son got a master's degree in a really good university and got back to the hometown with less than 5000 RMB a month? If you do not work hard and be better than others, you will find yourself working in a place you do not like at all.

Deep down, I know that my relationship with my parents follows the Confucian tradition in which individuals influence the social status of family numbers via sociocultural relations (Hall and Ames 1987). However, it was stressful to think about my future employment. Moreover, there is a misalignment between my parents and me - I had a consuming passion for acquiring knowledge, as I found that the charm of learning lay fundamentally in the appreciation of diverse schools of thoughts, instead of cultivating myself to become a qualified worker.

\subsection{Emailing with the tutor: a light of my life}

I acknowledged the value of engagement in e-learning environments. Thus, while I was struggling to join asynchronous discussion forums, I strived to involve myself in learner-lecturer interactions through sending emails regularly. Here is an extract from my email:

Mon, 16 Mar 2020, 08:43

Last week, I was learning tons of learning theories. As I am reflecting on all of them, I noticed that all theorists are striving to come up with a "general" learning pattern; in this sense, the sociocultural influence is being ignored. From my understanding, culture is not "pure", school may not be a "liberal" place. Bourdieu (1984) has claimed that education could become a "symbolic violence" as the dominant culture is belonging to the privilege status. Even Vygotsky, the great man who came out of the sociocultural constructivism theory, has no analyses of the identity of culture...... I am very interested in the social context and learning, how learners are being affected by the social force and how learning reflects the environment in which learners grow. I was thinking it will be fun to link multiple intelligence theory with different types of society, or add a bit analysis in Vygotsky's theory, like how the social representation influences learners in different classes...

The tutor replied to me an hour later: 
Thanks for sharing your critical thoughts with me, which are so interesting. Yes, you're right. I definitely agree with you that identity and culture have huge impacts on learners' learning development. You can deepen your understanding and reflection about the influence of culture, identity and/or multicultural education when we explore Module 4 in this unit with me.

Writing to the tutor on a regular basis helps me maintain a level of motivation, especially when the tutor always replies to me positively. However, she did not make any connections with peers and I explored the course alone. I would feel motivated for days and immersed myself into the knowledge. These moments were so enjoyable that I could forget the fact that I am isolated in a small room. When I received the final feedback by the chief examiner, who remarked "Overall, it's an excellent task", I was tearful. I could not figure out whether I was happy with my achievement, or sad because of the emotional e-learning journey.

Despite my first-rate academic result, in my e-learning experience my expectations were not achieved, particularly because of the ineffective emotional consumption and interactions, i.e., e-learning engagement, cultural conflicts and the sense of control. In other words, I perceived the development of the virtual university as a practical but unpleasant alternative in the pandemic, and preferred to avoid the e-learning experience in the future. There was a conflict between my ego and superego, and I was longing for a change.

\section{Discussion}

This section applies the 3P model to expound on the inner logic behind the participant's learning behaviours (see more explanation about this model in the literature review). Biggs' 3P model (Biggs, 1990), in this sense, can be a means of construing the relationship between learning behaviours and Australia's virtual universities by re-evaluating the nature of e-learning and the socioeconomic capital of international students. While the fundamental structure of the model is suitable in the current context, some modifications are still needed so that the model could be a better fit for online courses in Australia's virtual universities. There are two primary reasons for this. First, study-related factors, which means the ability and prior knowledge, may limit the investigation of Asian learners regarding their disposition toward learning technologies. Second, during the global pandemic, the connection between international students and the host country could become tenuous due to the quarantine regulations. It has been found that people in quarantine can suffer from psychological and immediate stress (Auerbach and Miller, 2020). Furthermore, international students may also lack social support from the host country, which can intensify their feelings of depression, separation and ultimately homesickness (Saravanan, Mohamad and Alias, 2019). Thus, they may tend to contact family members and connect to the home country on a more regular basis. These behaviours could add weight to the home country's sociocultural influence on their cross-border learning experience. Therefore, attention to the technicalsociocultural environment and the participant's socioeconomic status in her home country was included in the present study. Moreover, the elements of the teaching context in the original model were replaced by the situational context in this study so that a broader range of elements during the pandemic could be explored. Given that, the 3P model would be treated with caution in the following discussion.

\subsection{The presage}

Presage, in the present study, intends to explore the participant's demographic variables and situational variables. Traditionally, Asian learners have been seen as rote learners who adopt surface learning approaches and demonstrate a heavy reliance on textbooks (Ramburuth and McCormick, 2001). While this assumption has been refuted by later studies (Hojo and Oshio, 2012), researchers continue to argue that Asian learners tend to be passive in classes (Zhao and McDougall, 2008). For example, the participant in this study devoted a vast amount of time to familiarise herself with the learning context and showed little enthusiasm for interaction in online discussion forums. Such behaviours seem to echo the traditional image of an Asian learner. Based on this inclination, researchers suggest that Asian learners may not possess the required characteristics for academic success in western learning environments. However, this notion could be denied in this case as the participant achieved high marks. This apparent inconsistency could be explained through drawing on Bourdieu's (1996) analysis, the disposition of learners reflects the nature of their learning environment. In Asian countries, while the development of learners' communication skills has increasingly come to educators' and policymakers' attention, mainstream educational practices remain test-driven (Lee, 2017). Within this environment, diligence, 
as a favourable quality, is cultivated, strengthened and maintained by local educators and has become one of the most distinctive personal characteristics of the participant, an Asian international student.

The demographic variables, in this study, intertwine with the situational variables which could present in the form of situational interest (Quinlan, 2019). Statistics show that for every 100 people in China there were 19 computers in 2001, whereas the number was reported as 68.236 computers for 100 people in Australia in the same year (Hamidi et al., 2011). It suggests the minimal chance of the participant to foster digital skills. The participant could be more vulnerable to technical problems and issues in the e-learning environment. However, the main issues were not particularly related to technical skills, but more to individual factors such as the uncertainty about online communication and time-management skills. As such, the participant presented a low level of situational interest and thus struggling to embrace the e-learning approach - engaging with the discussion forum - and experienced overloaded information from the learning contents. Such a situation is worsened in the time of COVID-19, where students allow little time to prepare, learn and master basic e-learning skills. Drawing on Bourdieu's (1984) concept of capital, which refers to the internalised aptitude and externalised scarce social resources of the current study, the participant lacked the 'digital capital' to operate technologies and evaluate information. This then points to the insufficient social capital that the participant possessed and uncovers the issue of inequality in online education.

In the current context, the 3P model is expended to account for a wider range of presage variables, such as situational factors in both home country and host country. Indeed, the participant, as an economically advantaged learner, was supposed to be endowed with 'digital capital'. While she can be classified in an advantaged group in her home country, it is questionable whether she can fall into the same category in Australia. In such a setting, the possession of digital capital is advantageous, for the learning field is reorganised so that learners with digital capital can benefit by acquiring desired knowledge with less effort; they can practice e-learning in a more flexible and versatile manner than their counterparts for their better digital skills. In this regard, the emergence of virtual universities during the pandemic blurs the original boundary of the field, disrupts the logic within these relative static sociologies of classes and re-forms the learning field (Roger, 2003). In view of the above discussion, one may acknowledge that the academic performance of the participant, as an Asian international student, may be compromised in the virtual university.

\subsection{The process}

The second stage of the 3P model, the process, concerns the student's learning strategies. Following Biggs' (1990) differentiation, there are three approaches to learning: surface approach, deep approach and achieving approach. By definition, the first one refers to the effort that requires to meet basic requirements, while the followed one means the sustained engagement of learners to think critically and analyse the relationship between content knowledge and practice. The last one describes these learning behaviours that aim to maximise students' academic results. With regard to the learning expectation of the participant, it is argued that her focuses were predominately placed on mastering the unit-based content and obtaining high scores in the assignments, thereby discarding the deep approach to learning. Thus, the participant's cohort, Asian students, were commonly labelled as surface and rote learners. However, the conceptualisation of memorising differs according to cultural contexts (Biggs, 1990), thereby causing the paradoxical description of Asian students, that is, rote learners on the one hand, and brainy Asians on the other hand. These inconsistent perceptions of Asian students imply the intrinsic distinctions between learning contexts. In this sense, the participant is likely to confront challenges concerning cultural difference.

Given the cultural background - Confucian - of the participant, she firstly engaged in learning activities by taking a surface approach. For example, she strived to master the course content by engaging with learning materials, such as recorded lecturing. However, she also adopted a deep approach as a means to enhance understanding. For instance, she would seek supplementary articles to extend the content of the course and attempted to apply acquired knowledge to real-life events. During this process, the teaching practices, such as theoretical scaffolds, and the use of guiding questions assisted the learner to expand and refine her reasoning. In the narrative, she presented her initiative by emailing the tutor. This practice was proven to be helpful, because she described it as the light of her e-learning experience. Overall, these practices indicate the participant's dispositional belief of being able to cope with content-related challenges and characterise her as a deep learner.

As a critical aspect of learning strategies, the learning engagement strategy has a profound impact on a learner's encoding process and consequently determines the learning outcome (Simelane and Mji, 2014). In the current 
online learning environment, learners are praised for their active participation, especially in Australia's courses, where real-life professional contexts are emphasised, and cultural interpretations of the content knowledge are commonly accepted. Led by her parents' extreme academic expectations, the participant employed a partially strategic approach, such as devoting consistent efforts toward learning and connecting with the lecturer for guidance.

However, the learning story alluded to the fact that the participant failed to engage socially with her peers and instead employed a low-profile approach to e-learning, suggesting poor management of time and effort. Arguably, the participant utilised the strategic approach sparingly. However, such learning behaviours could be due to the possibly impersonal nature of the e-learning environments that lack non-verbal cues (Orton-Johnson, 2008). Non-native English speakers, especially those with an Asian background, may confront cultural challenges as they are used to being immersed in high-context environments where communication primarily relies on nonverbal cues. Recognising this fundamental shortcoming in this cohort would help course designers to explore ways that would better assist learners in engaging with their cohort. This would take into account Asian students' national, cultural and ethnic characteristics.

\subsection{The product}

The product, in this study, refers not only to the participant's academic achievement but also her formulated perception of Australia's virtual university in terms of its effectiveness and practical functions. According to Biggs' (1990) prediction, academic performance would be correlated positively with the use of the achieving approach and deep approach while it would correlate negatively with the surface approach. Superficially, the finding is contrary to Biggs' prediction, as the participant had a high-Grade Point Average regardless of her neglecting to use the achieving approach. Meanwhile, the finding also differs from the Vygotskian principle, that is, the positive learning outcome is only attainable by reforming and synthesising the existing knowledge framework (Vygotsky, 1998). Despite the seeming controversies in the product regarding whether or not the participant was a successful e-learner, the fact that the struggles in presage and process, and the underachieved expectation of the participant suggests that her product could not be defined solely by the academic result.

The participant's failure to derive satisfaction from e-learning implies the limitations of her practices. This finding is echoed by Wang and Chiu (2008), who contend that unsatisfactory e-learning is likely to result from low-level cognitive engagement with context, which may be caused by underdeveloped socio-emotional intelligence. Hence, the intrinsic weaknesses of the participant combined with her socio-economic background, i.e. the insufficient engagement with the cohort, to some extent, could make her an underdeveloped learner in the virtual university.

In previous studies, discussion on the 3P model product were limited to course grades and rarely considered learners' perceptions toward the course. With the rapid flourish of the virtual university, e-learners' perceptions of courses have become one of the most investigated learning outcomes (Helmi, 2001), and thus, could be another form of the product. Thus, the present study tracked the participant's understanding of the virtual university with reference to sociocultural elements. For Asian international students, the acquisition of knowledge from western universities is essentially the quest for positional goods. Therefore, when evaluating the effectiveness of receiving online courses from Australia's virtual universities, the role of sociocultural networks from the participant's original country needs to be taken into account.

In the participant's narrative, insights into how cultural values are rooted in her social networks, such as the connections from home, is provided. For example, her parents have a pragmatic attitude towards education and treat education experience in Australia as leverage in the labour market. While education is considered as the cultivation of talents and the improvement of their productivity by the human capital theory (Stigler, 1987), some scholars highlight that education provides a signal of scarcity for employers (Pham and Tran, 2015). Such a view is in line with the precited effectiveness of virtual university, as both of them assume the asymmetric information structure between the labour market and the schooling. In this sense, evaluation of the virtual university is based on its effectiveness in the labour market regarding whether the educational product could symbolise the absolute levels of productivity and thus gain the monetary returns. In this regard, the emergence of virtual universities may expand the potential competitor cohort due to its affordability, meaning that more people would be able to access the knowledge through e-learning with lower cost. Given the sociocultural influence from the participant's original country and her individual factors, she was struggling to engage with 
peers through e-learning models through having had insufficient e-practices. In a sense, she cannot utilise elearning tools effectively, and as a result, she formed a negative attitude toward virtual universities as a whole.

\section{Conclusion}

This article outlines a learning episode of an Asian student's e-learning experience at an Australian university during the COVID-19 pandemic. Although the findings from the study deal explicitly with an Asian learner, they provide an important insight into the development of online education and present a clearer picture of internationalised higher education than is usually described. This study offers a more detailed observation of international students via applying the 3P model. In particular, it focuses on sociocultural conflict and offers a fuller meaning of issues around inequality during a pandemic in the space of higher education. A visible constraint of the present study is that the findings are based on a single sample, which may affect some overgeneralisation about the cohort of international students studying in Australia.

The findings of the study would be very useful in a number of ways. Specifically, the findings could inspire educators and could innovate the existing e-practices in an internationalised virtual classroom, help international students to adjust and develop e-learning habits and promote the design of e-learning as a whole. Not only does this make a contribution to the understanding of Asian students' e-learning habits, but also potentially it does make a theoretical contribution to the development of the 3P model. We hope that this study will lead to further academic research on international students' e-learning and their e-practice in internationalised universities.

\section{References}

Adams, T.,Holman J.S., and Ellis, C., 2015. Autoethnography. New York, NY: OUP.

Anderson, L., 2006. Analytic autoethnography. Journal of Contemporary Ethnography, 35(4), pp. 373-395.

Arbaugh, J.B., 2004. Learning to learn online: a study of perceptual changes between multiple online course experiences. The Internet and Higher Education, 7(3), pp.169-182.

Auerbach, J. and Miller, B., 2020. COVID-19 exposes the cracks in our already fragile mental health system. American Journal of Public Health, 110 (7), pp. 969-970.

Australian Bureau of Statistics, 2020, Australian national accounts: National income, expenditure and product. Available at $<$ https://www.abs.gov.au/> [Accessed 3 June 2020]

Australian Government Department of Education Skills and Employment, 2020. Coronavirus (COVID-19) information for schools and students. Available at: https://ww w.dese.gov.au/covid-19/schools

Bernard, R., Abrami, P., Lou, Y., and Borokhovski, E., 2004. A methodological morass? How we can improve quantitative research in distance education. Distance Education, 25 (2), pp. 175-198.

Biggs, J.,1990. Individual differences in study processes and the quality of learning outcomes. Higher Education, 8, pp. 381394.

Bourdieu, P., 1984, Distinction: A social critique of the judgement of taste. Cambridge MA.: Harvard University Press.

Bourdieu, P., 1996, The state nobility: Elite school in the field of power. Cambridge MA.: Polity Press

Bullough, R.V. and Pinnegar, S., 2001. Guidelines for quality in autobiographical forms of self-study research. Educational Researcher, 30 (3), pp. 13-21.

Braun, V. and Clarke, V., 2006. Using thematic analysis in psychology. Qualitative research in psychology, 3(2), pp.77-101.

Chang, H., Ngunjiri, F.W., and Hernandez, K. C., 2013.. Walnut Creek, CA: Left Coast Press.

Chang, H., 2008. Autoethnography as method. Walnut Creek, CA: Left Coast Press.

Cho, Y.H., Choi, H., Shin, J., Yu, H.C., Kim, Y.K. and Kim, J.Y., 2015. Review of research on online learning environments in higher education. Procedia - Social and Behavioral Sciences, 191, pp. 2012-2017.

Ellis, C., 1997. Evocative autoethnography: Writing emotionally about our lives. In: W. Tierney, and Y. Lincoln (eds), Representation and the text: re-framing the narrative voice. Albany, NY: State University of New York.

Hamidi, F., Ghorbandordinejad, F., Rezaee, M. and Jafari, M., 2011. A comparison of the use of educational technology in the developed/developing countries. Procedia Computer Science, 3(C), pp. 374-377.

Harrington, L. and Liu, J.H., 2002. Self-enhancement and attitudes toward high achievers. Journal of Cross-cultural Psychology, 33(1), pp.37-55.

Hayano, D., 1979. Auto-ethnography: paradigms. problems and prospects. Human Organization, 38(1), pp. 99-104.

Helmi, A., 2001. An analysis on the impetus of online education: Curtin University of Technology, Western Australia. The Internet and Higher Education, 4 (3-4), pp. 243-253.

Hew, K. and Cheung, W., 2012. Students' use of asynchronous voice discussion in a blended-learning environment: a study of two undergraduate classes. Electronic Journal of E-Learning, 10 (4), pp. 360-367.

Hojo, M. and Oshio, T., 2012. What factors determine student performance in East Asia? New evidence from the 2007 trends in international mathematics and science study: East Asian student-performance factors. Asian Economic Journal, 26 (4), pp.333-357. 
Ke, F. and Kwak, D., 2013. Online learning across ethnicity and age: a study on learning interaction participation, perception, and learning satisfaction. Computers \& Education, 61 (1), pp. 43-51.

King, R. and Sondhi, G., 2018. International student migration: a comparison of UK and Indian students' motivations for studying abroad. Globalisation, Societies and Education, 16(2), pp.176-191.

Lee, K., 2017. Rethinking the accessibility of online higher education: a historical review. The Internet and Higher Education, 33, pp. 15-23.

Lin, Y., and Chan, P.W.K., 2020. Class origins, higher education and employment in China during the 21st century. Higher Education Quarterly, 00, pp. 1-14

McPherson, M.S. and Bacow, L.S., 2015. Online higher education: beyond the hype cycle. Journal of Economic Perspectives. 29 (4), pp. 135-154.

Orton-Johnson, K., 2008. The online student: Lurking, chatting, flaming and joking. Sociological Research Online, 12 (6), pp. $1-11$.

Parliament of Australia 2019,. Overseas students in Australian higher education: a quick guide. viewed 20 June 2019, https://www.aph.gov.au/About Parliament/Parliamentary Departments/Parliamentar y Library/pubs/rp/rp1819/Quick Guides/OverseasStudents.

Pham, L. and Tran, L., 2015. Understanding the symbolic capital of intercultural interactions: a case study of international students in Australia. International Studies in Sociology of Education, 25, PP. 204-224

Quinlan, K.M., 2019. What triggers students' interest during higher education lectures? personal and situational variables associated with situational interest. Studies in Higher Education: The Role of Emotions in Higher Education Teaching and Learning Processes, 44 (10), pp. 1781-1792.

Ramburuth, P. and Mccormick, J., 2001. Learning diversity in higher education: A comparative study of Asian international and Australian students. Higher Education, 42 (3), pp.333-350.

Saravanan, C. Mohamad, M. and Alias, A., 2019. Coping strategies used by international students who recovered from homesickness and depression in Malaysia. International Journal of Intercultural Relations, 68, pp. 77-87.

Shahtalebi, S. Shatalebi, B. and Shatalebi, F., 2011. A strategic model of virtual university. Procedia Social and Behavioral Sciences, 28, pp. 909-913.

Simelane, S. and Mji, A., 2014. Impact of technology-engagement teaching strategy with the aid of clickers on student's learning style. Procedia - Social and Behavioral Sciences, 136 (C), pp. 511-521.

Stigler, G., 1987, The theory of price. New York: Macmillan.

Eileen Tuk-ha, T. 2013. The quest for higher education by the Chinese middle class. Higher Education, 66(6), pp.653-668.

Vygotsky, L.S., 1998. Collected works, volume five. New York: Plenum.

Wang, J.C. and Chiu, C.C., 2008. Recommending trusted online auction sellers using social network analysis. Expert Systems with Applications, 34 (3), pp.1666-1679.

Zhao, N. and McDougall, D., 2008. Cultural influences on Chinese students' asynchronous online learning in a Canadian university. Journal of Distance Education, 22 (2), pp. 59-80. 